\title{
Is the Clinical Risk Score for Patients with Colorectal Liver Metastases Still Useable in the Era of Effective Neoadjuvant Chemotherapy?
}

\author{
Ninos Ayez, $\mathrm{MD}^{1}$, Zarina S. Lalmahomed, $\mathrm{MD}^{2}$, Anne E. M. van der Pool, $\mathrm{MD}^{1}$, Yvonne Vergouwe, $\mathrm{PhD}^{3}$, Kees van \\ Montfort, $\mathrm{PhD}^{4}$, Jeroen de Jonge, MD, $\mathrm{PhD}^{1,2}$, Alexander M. M. Eggermont, MD, $\mathrm{PhD}^{5}$, Jan N. M. IJzermans, MD, \\ $\mathrm{PhD}^{2}$, and Cornelis Verhoef, $\mathrm{MD}, \mathbf{P h D}^{1}$ \\ ${ }^{1}$ Division of Surgical Oncology, Erasmus University MC, Daniel den Hoed Cancer Center, Rotterdam, The Netherlands; \\ ${ }^{2}$ Division of Transplantation and Hepatobiliary Surgery, Erasmus University MC, Rotterdam, The Netherlands; ${ }^{3}$ Division \\ of Public Health, Center for Medical Decision Making, Rotterdam, The Netherlands; ${ }^{4}$ Division of Biostatistics, Erasmus \\ University MC, Daniel den Hoed Cancer Center, Rotterdam, The Netherlands; ${ }^{5}$ Institut de cancérologie Gustav Roussy, \\ Villejuif, France
}

\begin{abstract}
Background. Several clinical risk scores (CRSs) for the outcome of patients with colorectal liver metastases have been validated, but not in patients undergoing neoadjuvant chemotherapy. Therefore, this study evaluates the predictive value of these CRSs in this specific group.

Methods. Between January 2000 and December 2008, all patients undergoing a metastasectomy were analyzed and divided into two groups: 193 patients did not receive neoadjuvant chemotherapy (group A), and 159 patients received neoadjuvant chemotherapy (group B). In group B, the CRSs were calculated before and after administration of neoadjuvant chemotherapy. Results were evaluated by using the CRSs proposed by Nordlinger et al., Fong et al., Nagashima et al., and Konopke et al.

Results. In groups $\mathrm{A}$ and $\mathrm{B}$, the overall median survival was 43 and 47 months, respectively $(P=0.648)$. In group $\mathrm{A}$, all CRSs used were of statistically significant predictive value. Before administration of neoadjuvant chemotherapy, only the Nordlinger score was of predictive value. After administration of neoadjuvant chemotherapy, all CRSs were of predictive value again, except for the Konopke score.

Conclusions. Traditional CRSs are not a reliable prognostic tool when used in patients before treatment with
\end{abstract}

(C) The Author(s) 2011. This article is published with open access

at Springerlink.com

First Received: 23 December 2010;

Published Online: 3 June 2011

C. Verhoef, MD, PhD

e-mail: c.verhoef@erasmusmc.nl neoadjuvant chemotherapy. However, CRSs assessed after the administration of neoadjuvant chemotherapy are useful to predict prognosis.

In patients with colorectal cancer, about $50-60 \%$ will develop metastatic disease. Synchronous metastases are present in $25 \%$ of colorectal cancer patients. ${ }^{1,2}$ Nowadays, neoadjuvant chemotherapy is increasingly used for patients with colorectal liver metastases (CRLM). New systemic regimes are highly effective, and response rates of 50-80\% have been reported; they appear to convert $10-30 \%$ of the formerly irresectable CRLM to a resectable size. ${ }^{3-6}$ Several clinical risk scores (CRSs) for the outcome of patients with CRLM have been published. ${ }^{7-16}$ A CRS is a predictive tool for patients with CRLM who undergo resection. ${ }^{4,8-12,17-22}$ CRSs were initially used to predict the prognosis of patients with CRLM considered for surgery. In addition, CRSs are used to stratify patients into risk categories, to compare patient cohorts from different studies and institutions, and to select patients for different treatment protocols.

However, the predictive value of these CRSs has not been assessed in the specific group of patients receiving neoadjuvant chemotherapy before resection of CRLM. It is possible that the traditional CRSs, applied before administration of neoadjuvant chemotherapy, may no longer be capable of correctly predicting the outcome in patients receiving neoadjuvant chemotherapy., 19,20

Therefore, in the present study, four widely used CRSs are applied in a cohort of patients with CRLM who received neoadjuvant chemotherapy before resection, to 
evaluate whether neoadjuvant chemotherapy influences the predictive value of CRSs.

\section{PATIENTS AND METHODS}

Between January 2000 and December 2008, all consecutive patients who underwent liver resection for CRLM were analyzed. Patient characteristics were collected retrospectively from a prospectively recorded database. Two groups were created: group A (patients without neoadjuvant chemotherapy; $n=193$ ) and group B (patients with neoadjuvant chemotherapy; $n=159$ ). In group $\mathrm{B}$, the CRSs were calculated before (B1) and after (B2) administration of neoadjuvant chemotherapy.

The prospective database comprises data on age, gender, primary tumor site, pathological primary tumor and lymph node stage, time between detection of primary tumor and liver metastases, type of surgery, location, maximum number and size of liver metastases on computed tomographic scan and pathology, carcinoembryonic antigen (CEA) levels, radicality of surgical margin, and extrahepatic disease.

Ours is a referral hospital; perioperative chemotherapy is not administered as a standard treatment protocol for patients with CRLM. Most of our patients have already received neoadjuvant chemotherapy in the referring hospital. In our center, the indication for neoadjuvant chemotherapy is twofold: in case of initially difficult/unresectable liver metastases, or in case of multiple synchronous metastases numbering $\geq 4$. It is our policy not to resect in case of tumor progression during chemotherapy. Neoadjuvant chemotherapy protocols comprise oxaliplatin-based combination therapies with or without bevacizumab. None of the patients in the present study received adjuvant chemotherapy. The duration of the chemotherapy was at minimum 3 cycles. If there were resectable metastases, chemotherapy was given to a maximum of 6 cycles or was stopped after 3 cycles in case of disappearing metastases. In case of unresectable disease, chemotherapy was provided until resectable status was achieved.

\section{CRSs}

Four widely used CRSs were evaluated (Table 1). ${ }^{8,9,11,12}$ The Nordlinger score includes seven risk factors and defines three risk groups, but, as proposed by Nordlinger et al., we used only six risk factors. Fong's score includes five risk factors and defines two risk groups. Nagashima's score includes five risk factors and defines three risk groups. The Konopke score includes three risk factors and defines three risk groups. These four CRSs were applied on our data to evaluate each of the scores.

\section{Outcome}

Overall survival (OS) was defined as the interval (in months) between resection of CRLM and death, or the date of last follow-up. Disease-free survival (DFS) was defined as the interval (in months) between resection of CRLM and intra- and/or extrahepatic recurrence, death without recurrence, or date of last follow-up without recurrence.

\section{Statistical Analysis}

Descriptive statistics are expressed as median (range). Comparison between the categorical variables was made with the chi-square test. Pre- and postchemotherapy variables are expressed as mean \pm standard deviation (SD) and compared with the paired $t$-test. Survival analysis was performed by the Kaplan-Meier method. Comparison between survival curves was made with log rank tests. For missing values, multiple imputation was used.

SPSS software, version 17.0 (SPSS, Chicago, IL), was used for statistical analysis; a $P$-value of $\leq 0.05$ is considered statistically significant.

\section{RESULTS}

Between January 2000 and December 2008, a total of 352 patients underwent liver resection for CRLM (Table 2). The median follow-up was 32 (range 0-121) months. Median age was 63 (range 30-86) years. The clinical characteristics are presented in Table 2. The median DFS was 11 (95\% confidence interval [CI] 9-13) months, and the median OS was 46 (95\% CI 39-53) months. Neoadjuvant chemotherapy was provided to 159 patients $(45.2 \%)$. Chemotherapy was given in a median of 6 (1-15) courses. In total, 43 patients received more than 6 courses with a median of 9 (7-15) courses.

\section{Pre-and Postchemotherapy}

In patients receiving neoadjuvant chemotherapy, the variables size of metastases, CEA level, number of metastases, bilobar disease, and extrahepatic disease were analyzed before and after administration of neoadjuvant chemotherapy. Before neoadjuvant chemotherapy, the mean \pm SD size, CEA level, and number of metastases were $3.98 \pm 2.62 \mathrm{~cm}, 171 \pm 568 \mu \mathrm{g} / \mathrm{l}$ and $3.19 \pm 1.95$, respectively. Before neoadjuvant chemotherapy, 83 patients had bilobar disease and 22 had extrahepatic disease. After neoadjuvant chemotherapy, the mean \pm SD size, CEA level, and number of metastases were $2.83 \pm 2.45 \mathrm{~cm}, 21 \pm 48 \mu \mathrm{g} / \mathrm{l}$ and $2.64 \pm 1.96$, respectively. After chemotherapy, 81 patients had bilobar disease 
TABLE 1 Clinical risk score

\begin{tabular}{|c|c|c|c|}
\hline Scale & Clinical score criteria $^{a}$ & Criteria & Score \\
\hline Nordlinger & $\begin{array}{l}\text { 1. Age } \geq 60 \text { years } \\
\text { 2. Extension into the serosa of the primary cancer } \\
\text { 3. Lymphatic spread of the primary cancer } \\
\text { 4. Interval less than } 2 \text { years from primary tumor to } \\
\text { metastases } \\
\text { 5. Number of metastases } \geq 4 \\
\text { 6. Largest size of liver metastasis } \geq 5\end{array}$ & $\begin{array}{l}\text { Exclusion criteria } \\
\text { 1. Incomplete liver tumor resection } \\
\text { 2. Extrahepatic tumor involvement }\end{array}$ & $\begin{array}{l}\text { - } 0-2 \text { risk factors "low } \\
\text { risk" } \\
\text { - } 3-4 \text { risk factors } \\
\text { "intermediate risk" } \\
\text { - 5-6 risk factors "high } \\
\text { risk" }\end{array}$ \\
\hline Fong & $\begin{array}{l}\text { 1. Number of liver metastases }>1 \\
\text { 2. Preoperative CEA level }>200 \mathrm{ng} / \mathrm{ml} \\
\text { 3. Largest size of liver metastasis } \geq 5 \\
\text { 4. Lymph node-positive primary tumor } \\
\text { 5. Interval from primary tumor resection to diagnosis of the } \\
\text { liver metastases }<12 \text { months }\end{array}$ & $\begin{array}{l}\text { Exclusion criteria } \\
\text { 1. Positive resection margin } \\
\text { 2. Preoperative extrahepatic disease }\end{array}$ & $\begin{array}{l}\bullet 0-2 \text { risk factors } \\
\bullet 3-4-5 \text { risk factors }\end{array}$ \\
\hline Nagashima & $\begin{array}{l}\text { 1. Serosal invasion of primary tumor } \\
\text { 2. Positive lymph node of primary tumor } \\
\text { 3. Number of hepatic metastases } \geq 2 \\
\text { 4. Diameter of hepatic metastases } \geq 5 \mathrm{~cm} \\
\text { 5. Resectable extrahepatic metastases. }\end{array}$ & $\begin{array}{l}\text { Inclusion criteria } \\
\text { 1. Expected radical excision (including } \\
\text { extrahepatic metastases) }\end{array}$ & $\begin{array}{l}-0-1 \text { grade } 1 \\
-2-3 \text { grade } 2 \\
\bullet \geq 4 \text { grade } 3\end{array}$ \\
\hline Konopke & $\begin{array}{l}\text { 1. Number of liver metastases } \geq 4 \\
\text { 2. CEA level }(\mathrm{ng} / \mathrm{ml}) \geq 200 \\
\text { 3. Synchronous liver metastases }\end{array}$ & $\begin{array}{l}\text { Exclusion criteria } \\
\text { 1. Recurrent liver metastases } \\
\text { 2. Simultaneous extrahepatic tumor } \\
\text { recurrence } \\
\text { 3. Simultaneous local ablative therapy } \\
\text { 4. Intraoperative dissemination of tumor } \\
\text { cells } \\
\text { 5. Macroscopically or microscopically } \\
\text { incomplete resection }\end{array}$ & $\begin{array}{l}-0 \text { low risk } \\
\text { - } 1 \text { intermediate risk } \\
-\geq 2 \text { high risk }\end{array}$ \\
\hline
\end{tabular}

CEA carcinoembryonic antigen

${ }^{\text {a }}$ Each criterion is assigned 1 point

and 22 patients still had extrahepatic disease. To determine the size of the metastases the postchemotherapy abdominal scans were assessed. To determine the number of metastases the postsurgery pathological report was examined. Only when complete response was reported did the number of metastases decrease. The difference between pre- and postneoadjuvant chemotherapy was significant for the size of metastases, CEA level, and the number of metastases ( $P<0.001, P=0.001$, and $P<0.001$, respectively). No significant difference was found between bilobar disease and extrahepatic disease before and after neoadjuvant chemotherapy ( $P=0.832$ and $P=0.999$, respectively).

\section{Nordlinger}

The CRS of Nordlinger could be applied to 150 patients in group A and to 101 patients in group B (Table 1).

In group A the median DFS was 16 (95\% CI 12-20) months, and the median OS was 48 (95\% CI 33-63) months (Tables 3,4). In group A, the Nordlinger score was of statistically significant predictive value. There was a significant difference between the CRS subgroups for DFS and $\mathrm{OS}$ ( $P=0.028$ and $P=0.006$, respectively). Because of the small numbers of patients, the CRS subgroup 3 (CRS 5-6) was pooled together with subgroup 2 (CRS 3-4). In group B the median DFS was 13 (95\% CI 9-17) months and the median OS was 65 (95\% CI 44-86) months. The Nordlinger score was of predictive value both before and after administration of neoadjuvant chemotherapy. In these CRS subgroups a significant difference was found in OS: $P=0.007$ before neoadjuvant chemotherapy and $P=0.010$ after neoadjuvant chemotherapy.

\section{Fong}

The CRS of Fong could be applied to 150 patients in group A and to 101 patients in group B (Table 1).

In group $A$ the median DFS was 16.0 (95\% CI 12-20) months, and the median OS was 48 (95\% CI 33-63) months (Tables 3, 4). There was a significant difference 
TABLE 2 Characteristics of the study patients

\begin{tabular}{|c|c|c|c|c|c|c|}
\hline \multirow[t]{2}{*}{ Characteristic } & \multicolumn{2}{|c|}{ All patients $(n=352)$} & \multicolumn{2}{|c|}{$\begin{array}{l}\text { Patients without chemotherapy } \\
\text { (group A) }(n=193)\end{array}$} & \multicolumn{2}{|c|}{$\begin{array}{l}\text { Patients with chemotherapy } \\
\text { (group B) }(n=159)\end{array}$} \\
\hline & Value & $\%$ or range & Value & $\%$ or range & Value & $\%$ or range \\
\hline Male & 218 & 62 & 122 & 63 & 96 & 60 \\
\hline Median age (years) & 63 & $30-86$ & 64 & $30-86$ & 62 & $36-84$ \\
\hline \multicolumn{7}{|l|}{ Primary tumor } \\
\hline Rectal cancer & 167 & 47 & 90 & 47 & 77 & 48 \\
\hline $\mathrm{T} 3$ & 259 & 74 & 140 & 73 & 119 & 75 \\
\hline $\mathrm{T} 4$ & 30 & 9 & 15 & 8 & 15 & 9 \\
\hline Missing before imputation & 6 & 2 & & & & \\
\hline Positive lymph node & 205 & 58 & 110 & 57 & 92 & 58 \\
\hline Missing before imputation & 6 & 2 & & & & \\
\hline \multicolumn{7}{|l|}{ Liver metastases } \\
\hline Synchronous & 172 & 49 & 55 & 29 & 117 & 74 \\
\hline Median diameter (cm) & 3.5 & $0.5-18$ & 3.5 & $0.9-15$ & 3.4 & $0.5-18$ \\
\hline Missing before imputation & 5 & 1 & & & & \\
\hline Median no. of metastases & 2 & $1-10$ & 1 & $1-8$ & 3.0 & $1-10$ \\
\hline Missing before imputation & 2 & 1 & & & & \\
\hline Bilobar & 135 & 38 & 52 & 27 & 83 & 52 \\
\hline Extrahepatic & 29 & 8 & 7 & 44 & 22 & 14 \\
\hline Incomplete resection & 72 & 21 & 40 & 21 & 32 & 20 \\
\hline Missing before imputation & 7 & 2 & & & & \\
\hline Overall survival (months) & 46 & $95 \%$ CI 39-53 & 43 & $95 \%$ CI 34-52 & 47 & $95 \%$ CI 33-61 \\
\hline Disease-free survival (monthos) & 11 & 95\% CI 9-13 & 14 & 95\% CI 11-17 & 9 & $95 \%$ CI 7-11 \\
\hline
\end{tabular}

CI confidence interval

between the CRS subgroups for DFS and OS $(P<0.001$ and $P=0.001$, respectively).

In group B the median DFS was 13 (95\% CI 9-17) months, and the median OS was 65 (95\% CI 44-86) months. Fong's score was not of statistically significant predictive value when calculated before neoadjuvant chemotherapy. In the CRS subgroups no significant difference was found for OS $(P=0.592)$. After neoadjuvant chemotherapy, a significant difference $(P=0.003)$ was found between the CRS subgroups for OS.

\section{Nagashima}

The CRS of Nagashima could be applied to 193 patients in group A and to 159 patients in group B (Table 1).

In group A, the median DFS was 14 (95\% CI 11-17) months and the median OS was 43 (95\% CI 34-52) months (Tables 3,4). In the CRS subgroups a significant difference was found for DFS and OS $(P=0.001$ and $P=0.001$, respectively). Because of the small numbers of patients, the CRS subgroup $3(\mathrm{CRS} \geq 4)$ was pooled together with subgroup 2 (CRS 2-3).
In group B, the median DFS was 9 (95\% CI 7-11) months and for OS the median was 47 (95\% CI 33-61) months. When calculated before neoadjuvant chemotherapy Nagashima's score was not of significant predictive value, and no significant difference $(P=0.122)$ was found between the CRS subgroups for OS. However, after neoadjuvant chemotherapy, a significant difference $(P=$ 0.001) was found between the CRS subgroups for OS.

\section{Konopke}

The CRS of Konopke could be applied to 145 patients in group A and to 69 patients in group B (Table 1).

In group A the median DFS was 16 (95\% CI 11-21) months, and the median OS was 51 (95\% CI 37-65) months (Tables 3, 4). Between the CRS subgroups a significant difference was found in DFS and OS $(P=0.002$ and $P=0.024$, respectively).

In group B the median DFS was 21 (95\% CI 3-39) months, and the median OS was 65 months (the 95\% CI could not be calculated by the SPSS software). There was no significant difference between the subgroups in OS, 
TABLE 3 Kaplan-Meyer analysis of disease-free survival in patients with and without chemotherapy

\begin{tabular}{|c|c|c|c|c|c|c|c|c|c|c|c|c|c|c|c|}
\hline \multirow[t]{2}{*}{$\begin{array}{l}\text { Scoring } \\
\text { system }\end{array}$} & \multicolumn{5}{|c|}{$\begin{array}{l}\text { Without neoadjuvant chemotherapy } \\
\text { (group A) }\end{array}$} & \multicolumn{5}{|c|}{$\begin{array}{l}\text { Before neoadjuvant chemotherapy } \\
\text { (group B1) }\end{array}$} & \multicolumn{5}{|c|}{$\begin{array}{l}\text { After neoadjuvant chemotherapy } \\
\text { (group B2) }\end{array}$} \\
\hline & $n$ & $\begin{array}{l}\text { Median } \\
\text { time } \\
\text { (months) }\end{array}$ & $\begin{array}{l}95 \% \\
\mathrm{CI}\end{array}$ & $\begin{array}{l}3 \text { years } \\
(\%)\end{array}$ & $P$-value & $n$ & $\begin{array}{l}\text { Median } \\
\text { time } \\
\text { (months) }\end{array}$ & $\begin{array}{l}95 \% \\
\mathrm{CI}\end{array}$ & $\begin{array}{l}3 \text { years } \\
(\%)\end{array}$ & $P$-value & $n$ & $\begin{array}{l}\text { Median } \\
\text { time } \\
\text { (months) }\end{array}$ & $\begin{array}{l}95 \% \\
\mathrm{CI}\end{array}$ & $\begin{array}{l}3 \text { years } \\
(\%)\end{array}$ & $P$-value \\
\hline Nordlinger & 150 & 16 & $12-20$ & 40 & $0.028^{\mathrm{a}}$ & 101 & 13 & $9-17$ & 36 & $0.458^{\mathrm{a}}$ & 101 & 13 & $9-17$ & 36 & $0.173^{\mathrm{a}}$ \\
\hline $0-2$ & 87 & 18 & $0-43$ & 46 & & 37 & 13 & $5-22$ & 38 & & 47 & 14 & $7-23$ & 40 & \\
\hline $3-4$ & 59 & 15 & $11-19$ & 34 & & 60 & 13 & $6-20$ & 36 & & 53 & 12 & $7-17$ & 33 & \\
\hline $5-6$ & 4 & 4 & $0-12$ & 0 & & 4 & 3 & $0-9$ & 0 & & 1 & - & - & - & \\
\hline Fong & 150 & 16 & $12-20$ & 40 & $<0.001$ & 101 & 13 & $9-17$ & 36 & 0.603 & 101 & 13 & $9-17$ & 36 & 0.096 \\
\hline $0-2$ & 123 & 21 & $3-39$ & 47 & & 54 & 13 & $3-23$ & 38 & & 70 & 14 & $6-22$ & 39 & \\
\hline $3-5$ & 27 & 10 & $8-12$ & 11 & & 47 & 12 & $7-17$ & 34 & & 31 & 7 & $3-11$ & 29 & \\
\hline Nagashima & 193 & 14 & $11-17$ & 35 & $0.001^{\mathrm{a}}$ & 159 & 9 & $7-11$ & 26 & $0.030^{\mathrm{a}}$ & 159 & 9 & $7-11$ & 26 & $0.001^{\mathrm{a}}$ \\
\hline $0-1$ & 112 & 18 & $10-26$ & 44 & & 61 & 13 & $6-20$ & 32 & & 72 & 14 & $8-20$ & 34 & \\
\hline $2-3$ & 77 & 10 & $7-13$ & 24 & & 94 & 7 & $5-9$ & 22 & & 84 & 6 & $5-7$ & 18 & \\
\hline$\geq 4$ & 4 & 11 & $5-17$ & 0 & & 4 & 6 & - & 25 & & 3 & 6 & - & - & \\
\hline Konopke & 145 & 16 & $11-21$ & 41 & 0.002 & 69 & 21 & $3-39$ & 45 & 0.354 & 69 & 21 & $3-39$ & 45 & 0.663 \\
\hline 0 & 91 & 37 & $12-61$ & 51 & & 13 & 41 & - & 61 & & 15 & 41 & $0-83$ & 59 & \\
\hline 1 & 47 & 14 & $10-18$ & 29 & & 38 & 21 & $0-44$ & 45 & & 46 & 20 & $6-34$ & 41 & \\
\hline$\geq 2$ & 7 & 9 & $0-22$ & 0 & & 18 & 6 & $0-14$ & 32 & & 8 & 6 & $0-14$ & 38 & \\
\hline
\end{tabular}

CI confidence interval, $C R S$ clinical risk score

${ }^{a}$ As a result of the small numbers of patients, CRS subgroup 3 (CRS $\geq 4$ ) was pooled together with subgroup 2 (CRS 2-3)

TABLE 4 Kaplan-Meyer analysis of overall survival in patients with and without chemotherapy

\begin{tabular}{|c|c|c|c|c|c|c|c|c|c|c|c|c|c|c|c|}
\hline \multirow[t]{2}{*}{$\begin{array}{l}\text { Scoring } \\
\text { system }\end{array}$} & \multicolumn{5}{|c|}{$\begin{array}{l}\text { Without neoadjuvant chemotherapy } \\
\text { (group A) }\end{array}$} & \multicolumn{5}{|c|}{$\begin{array}{l}\text { Before neoadjuvant chemotherapy } \\
\text { (group B1) }\end{array}$} & \multicolumn{5}{|c|}{$\begin{array}{l}\text { After neoadjuvant chemotherapy } \\
\text { (group B2) }\end{array}$} \\
\hline & $n$ & $\begin{array}{l}\text { Median } \\
\text { time } \\
\text { (months) }\end{array}$ & $\begin{array}{l}95 \% \\
\text { CI }\end{array}$ & $\begin{array}{l}5 \text { years } \\
(\%)\end{array}$ & $P$-value & $n$ & $\begin{array}{l}\text { Median } \\
\text { time } \\
\text { (months) }\end{array}$ & $\begin{array}{l}95 \% \\
\text { CI }\end{array}$ & $\begin{array}{l}5 \text { years } \\
(\%)\end{array}$ & $P$-value & $n$ & $\begin{array}{l}\text { Median } \\
\text { time } \\
\text { (months) }\end{array}$ & $\begin{array}{l}95 \% \\
\mathrm{CI}\end{array}$ & $\begin{array}{l}5 \text { years } \\
(\%)\end{array}$ & $P$-value \\
\hline Nordlinger & 150 & 48 & $33-63$ & 45 & $0.006^{\mathrm{a}}$ & 101 & 65 & $44-86$ & 53 & $0.007^{\mathrm{a}}$ & 101 & 65 & $44-86$ & 53 & $0.010^{\mathrm{a}}$ \\
\hline $0-2$ & 87 & 66 & $36-96$ & 51 & & 37 & 65 & NR & 66 & & 47 & 65 & $53-77$ & 65 & \\
\hline $3-4$ & 59 & 42 & $23-61$ & 39 & & 60 & 47 & $20-74$ & 46 & & 53 & 46 & $29-63$ & 41 & \\
\hline $5-6$ & 4 & 18 & $0-49$ & 0 & & 4 & 18 & NR & 0 & & 1 & - & - & - & \\
\hline Fong & 150 & 48 & $33-63$ & 45 & 0.001 & 101 & 65 & $44-86$ & 53 & 0.592 & 101 & 65 & $44-86$ & 53 & 0.003 \\
\hline $0-2$ & 123 & 64 & $40-88$ & 52 & & 54 & 55 & $37-73$ & 48 & & 70 & 65 & NR & 58 & \\
\hline $3-5$ & 27 & 34 & $31-37$ & 21 & & 47 & 65 & $9-121$ & 60 & & 31 & 29 & $16-42$ & 41 & \\
\hline Nagashima & 193 & 43 & $34-52$ & 38 & $0.001^{\mathrm{a}}$ & 159 & 47 & $33-61$ & 47 & $0.122^{\mathrm{a}}$ & 159 & 47 & $33-61$ & 47 & $0.001^{\mathrm{a}}$ \\
\hline $0-1$ & 112 & 54 & $38-70$ & 47 & & 61 & 55 & $39-71$ & 47 & & 72 & 65 & $43-87$ & 56 & \\
\hline $2-3$ & 77 & 33 & $23-43$ & 28 & & 94 & 43 & $18-68$ & 47 & & 84 & 335 & $26-44$ & 38 & \\
\hline$\geq 4$ & 4 & 34 & $20-48$ & 0 & & 4 & 23 & $8-37$ & 0 & & 3 & 23 & $20-26$ & 0 & \\
\hline Konopke & 145 & 51 & $37-65$ & 45 & 0.024 & 69 & 65 & NR & 56 & 0.092 & 69 & 65 & NR & 56 & 0.505 \\
\hline 0 & 91 & 66 & 39-93 & 52 & & 13 & NR & - & 60 & & 15 & NR & - & 63 & \\
\hline 1 & 47 & 42 & $36-48$ & 41 & & 38 & 65 & $44-86$ & 60 & & 46 & 65 & $41-89$ & 55 & \\
\hline$\geq 2$ & 7 & 41 & $18-64$ & 0 & & 18 & 32 & $27-37$ & 45 & & 8 & 32 & $12-52$ & 45 & \\
\hline
\end{tabular}

$C I$ confidence interval, $N R$ not reached, $C R S$ clinical risk score

a As a result of the small numbers of patients, CRS subgroup 3 (CRS $\geq 4$ ) was pooled together with subgroup 2 (CRS 2-3) 
either before or after administration of neoadjuvant chemotherapy ( $P=0.092$ and $P=0.505$, respectively).

\section{Survival Outcome after Neoadjuvant Chemotherapy}

Patients with a lower CRS after neoadjuvant chemotherapy, compared to before chemotherapy, had the same survival outcome as patients with the same score but who did not have chemotherapy. For Nagashima's score, patients with a lower CRS after neoadjuvant chemotherapy had an even better survival outcome than patients with the same score who did not undergo chemotherapy $(P=0.009)$.

\section{DISCUSSION}

Until now, CRSs have not been evaluated for patients undergoing neoadjuvant chemotherapy before resection of CRLM. The present study evaluated CRSs in patients who received neoadjuvant chemotherapy before resection of liver metastases, and in patients who did not receive neoadjuvant chemotherapy.

Our results confirm that the CRSs of Nordlinger, Fong, Nagashima and Konopke could be applied to patients without neoadjuvant chemotherapy; however, when assessed before neoadjuvant chemotherapy, not all the CRSs are applicable.

A recent study evaluated eight prognostic scoring systems whereas we examined only four CRSs. ${ }^{23}$ Our reason for not investigating more scoring systems was because we lacked data on some variables used for these scores. For example, the score of Ueno et al. uses a pathological factor 'tumor budding' which is not reported for all patients in our clinic. ${ }^{16}$ Rees et al. include the differentiation of the primary tumor in the score; however, because we are a referral center most patients had their primary tumor resected elsewhere and we were unable to obtain all information required for this score. ${ }^{14}$ Schindl et al. use specific laboratory findings in their score, but these variables were not available in our prospectively recorded database. $^{13}$

Generally, CRSs are not used to determine the possibility of surgery in a patient with CRLM, but mainly to assess the prognosis of this group of patients after successful surgery. To compare results of different studies, it is helpful to assess outcome with knowledge of disease severity. The CRSs can be helpful in these cases and are often used., ${ }^{24}$ However, use of effective neoadjuvant chemotherapy might influence the value of the widely used CRSs.

Small et al. hypothesized that the power of prediction of Fong's score is reduced as a result of the effects of chemotherapy. ${ }^{20}$ To our knowledge, the present study is the first to explore this hypothesis in a single-center database with four CRSs in patients treated with neoadjuvant chemotherapy. Our results support the finding that when the CRS is calculated before starting neoadjuvant chemotherapy it is of no predictive value; however, we demonstrate that the scores are applicable when the score is addressed after administration of neoadjuvant chemotherapy. Konopke et al. described 43 patients who received neoadjuvant chemotherapy. ${ }^{12}$ In their study, the factors concerning liver-related oncological status were determined intraoperatively. Konopke et al. also confirmed the prognostic value of their scoring system in the patients who received neoadjuvant chemotherapy. This means that the score was determined after receiving neoadjuvant chemotherapy so one would expect this score to be applicable. However, we could not demonstrate the same result in our group of patients.

In the present study, chemotherapy downstaged the size and the CEA level. When the pathology report was consulted and complete response was reported, then the number of metastases also decreased significantly from a mean of $3.19 \pm 1.95$ to $2.64 \pm 1.96(P<0.001)$. This effect changes the CRS. Patients who had a higher risk score before chemotherapy became patients with a lower risk score after chemotherapy, with an associated improved survival. Bilobar disease showed no statistically significant change after administration of neoadjuvant chemotherapy, and extrahepatic disease did not change at all.

In conclusion, in the era of effective neoadjuvant chemotherapy, the traditional CRSs may no longer be a reliable predictive tool. On the basis of our findings, if prediction of prognosis is required, all the traditional CRSs can be used if they are determined after treatment with neoadjuvant chemotherapy. If a prognosis is required before starting neoadjuvant therapy, only the Nordlinger CRS is of statistically significant prognostic value.

\section{CONFLICT OF INTEREST None.}

OPEN ACCESS This article is distributed under the terms of the Creative Commons Attribution Noncommercial License which permits any noncommercial use, distribution, and reproduction in any medium, provided the original author(s) and source are credited.

\section{REFERENCES}

1. Bengmark S, Hafstrom L. The natural history of primary and secondary malignant tumors of the liver. I. The prognosis for patients with hepatic metastases from colonic and rectal carcinoma by laparotomy. Cancer. 1969;23:198-202.

2. van der Pool AE, Lalmahomed ZS, Ozbay Y, et al. "Staged" liver resection in synchronous and metachronous colorectal hepatic metastases; differences in clinicopathological features and outcome. Colorectal Dis. 2009;12:e229-35. 
3. Adam R, Avisar E, Ariche A, et al. Five-year survival following hepatic resection after neoadjuvant therapy for nonresectable colorectal. Ann Surg Oncol. 2001;8:347-53.

4. Nikfarjam M, Shereef S, Kimchi ET, et al. Survival outcomes of patients with colorectal liver metastases following hepatic resection or ablation in the era of effective chemotherapy. Ann Surg Oncol. 2009;16:1860-7.

5. Scheele J, Altendorf-Hofmann A. Resection of colorectal liver metastases. Langenbecks Arch Surg. 1999;384:313-27.

6. Giacchetti S, Itzhaki M, Gruia G, et al. Long-term survival of patients with unresectable colorectal cancer liver metastases following infusional chemotherapy with 5-fluorouracil, leucovorin, oxaliplatin and surgery. Ann Oncol. 1999;10:663-9.

7. Minagawa M, Yamamoto J, Kosuge T, et al. Simplified staging system for predicting the prognosis of patients with resectable liver metastasis: development and validation. Arch Surg. 2007;142:269-76.

8. Nordlinger B, Guiguet M, Vaillant JC, et al. Surgical resection of colorectal carcinoma metastases to the liver. A prognostic scoring system to improve case selection, based on 1568 patients. Association Francaise de Chirurgie. Cancer. 1996;77:1254-62.

9. Fong Y, Fortner J, Sun RL, et al. Clinical score for predicting recurrence after hepatic resection for metastatic colorectal cancer: analysis of 1001 consecutive cases. Ann Surg. 1999;230:309-18.

10. Iwatsuki S, Dvorchik I, Madariaga JR, et al. Hepatic resection for metastatic colorectal adenocarcinoma: a proposal of a prognostic scoring system. J Am Coll Surg. 1999;189:291-9.

11. Nagashima I, Takada T, Matsuda K, et al. A new scoring system to classify patients with colorectal liver metastases: proposal of criteria to select candidates for hepatic resection. $J$ Hepatobiliary Pancreat Surg. 2004;11:79-83.

12. Konopke R, Kersting S, Distler M, et al. Prognostic factors and evaluation of a clinical score for predicting survival after resection of colorectal liver metastases. Liver Int. 2009;29:89-102.

13. Schindl M, Wigmore SJ, Currie EJ, et al. Prognostic scoring in colorectal cancer liver metastases: development and validation. Arch Surg. 2005;140:183-9.
14. Rees M, Tekkis PP, Welsh FK, et al. Evaluation of long-term survival after hepatic resection for metastatic colorectal cancer: a multifactorial model of 929 patients. Ann Surg. 2008;247: 125-35.

15. Lise M, Bacchetti S, Da Pian P, et al. Patterns of recurrence after resection of colorectal liver metastases: prediction by models of outcome analysis. World J Surg. 2001;25:638-44.

16. Ueno $\mathrm{H}$, Mochizuki $\mathrm{H}$, Hatsuse $\mathrm{K}$, et al. Indicators for treatment strategies of colorectal liver metastases. Ann Surg. 2000;231: 59-66.

17. Zakaria S, Donohue JH, Que FG, et al. Hepatic resection for colorectal metastases: value for risk scoring systems? Ann Surg. 2007;246:183-91.

18. Merkel S, Bialecki D, Meyer T, et al. Comparison of clinical risk scores predicting prognosis after resection of colorectal liver metastases. J Surg Oncol. 2009;100:349-57.

19. Reissfelder C, Rahbari NN, Koch M, et al. Validation of prognostic scoring systems for patients undergoing resection of colorectal cancer liver metastases. Ann Surg Oncol. 2009;16: 3279-88.

20. Small RM, Lubezky N, Shmueli E, et al. Response to chemotherapy predicts survival following resection of hepatic colorectal metastases in patients treated with neoadjuvant therapy. J Surg Oncol. 2009;99:93-8.

21. Arru M, Aldrighetti L, Castoldi R, et al. Analysis of prognostic factors influencing long-term survival after hepatic resection for metastatic colorectal cancer. World J Surg. 2008;32:93-103.

22. Mann CD, Metcalfe MS, Leopardi LN, et al. The clinical risk score: emerging as a reliable preoperative prognostic index in hepatectomy for colorectal metastases. Arch Surg. 2004;139: $1168-72$.

23. Sotiropoulos GC, Lang H. Clinical scoring systems for predicting outcome after surgery for colorectal liver metastases: towards a better multidisciplinary approach. Liver Int. 2009;29:6-9.

24. Mentha G, Terraz S, Morel P, et al. Dangerous halo after neoadjuvant chemotherapy and two-step hepatectomy for colorectal liver metastases. Br J Surg. 2009;96:95-103. 